\title{
Inhibitor of apoptosis protein-like protein-2: A novel growth accelerator for breast cancer cells
}

\author{
LIN ZHU ${ }^{1}$, WEIHUA ZHOU ${ }^{1}$, XIDI ZHU ${ }^{1}$, SIQI XIANG $^{2}$, SIYUAN WANG $^{1}$, YINGXIA PENG ${ }^{3}$, BANGYUN LU $^{4}$, \\ PEIZHI TANG ${ }^{3}$, QIAN CHEN ${ }^{3}$, MENGJUAN WU $^{1}$, XIA PENG $^{1}$, ZIYU CHEN $^{1}$, ZIYI SUN ${ }^{1}$, \\ KUNLIANG YANG $^{1}$, MINGJUN XIANG ${ }^{1}$ and DANDAN YU ${ }^{1}$ \\ ${ }^{1}$ Department of Biochemistry and Immunology, Medical Research Center, Institute of Medicine, Jishou University, Jishou, \\ Hunan 416000; ${ }^{2}$ Department of Bioengineering, Biological Science and Engineering School, North University of \\ Nationalities, Yinchuan, Ningxia 750021; ${ }^{3}$ The First Affiliated Hospital, Institute of Medicine, Jishou University; \\ ${ }^{4}$ Tumor Hospital, Xiangxi Autonomous Prefecture, Jishou, Hunan 416000, P.R. China
}

Received January 10, 2018; Accepted July 23, 2018

DOI: 10.3892/or.2018.6626

\begin{abstract}
Although the inhibitor of apoptosis protein-like protein-2 (ILP-2) has been shown as a serological biomarker for breast cancer, its effect on breast cancer cell growth remains elusive. The present study aimed to determine the role of ILP-2 in breast cancer cell growth. We used immunohistochemistry to analyze ILP-2 expression in 59 tissue paraffin-embedded blocks, which included 35 breast cancer tissues and 24 galactophore hyperplasia tissues. Western blot analysis was used to detect protein expression levels of ILP-2 in breast cancer cell lines such as HCC-1937, MX-1 and MCF-7 as well as breast gland cell line MCF 10A. ILP-2 was silenced by siRNA in HCC-1937, MX-1 and MCF-7 cell lines. MTT assays, scratch assays and AO-EB double staining analysis were conducted to evidence the role of ILP-2 on breast cancer cell growth. Results from this study showed increased ILP-2 expression in breast cancer tissues and breast cancer cell lines such as HCC-1937, MX-1 and MCF-7. Cell viability or rate of cell migration of HCC-1937, MX-1 and MCF-7 cell lines was significantly inhibited when ILP-2 was knocked down by siRNA. The apoptosis rate of HCC-1937, MX-1 and MCF-7 cell lines was increased when compared with that of the control group. Thus, ILP-2 plays an active role in the growth of breast cancer cells.
\end{abstract}

\section{Introduction}

Inhibitors of apoptosis proteins (IAPs) are involved in cell death, migration and cell cycle (1). They exhibit an important

Correspondence to: Professor Mingjun Xiang, Department of Biochemistry and Immunology, Medical Research Center, Institute of Medicine, Jishou University, 120 South Renmin Road, Jishou, Hunan 416000, P.R. China

E-mail:xmj688@163.com

Key words: ILP-2, breast cancer cells, HCC-1937, MX-1, MCF-7 role in maintaining the balance between cell death and cell growth $(2,3)$. IAPs may effectively suppress cell apoptosis and promote cell growth (4). Additionally, IAP deregulation may accelerate cell canceration and provide a new target for anticancer therapy (5).

Following identification of the first human IAP protein, neuronal apoptosis inhibitory protein (NAIP) (6), eight proteins of IAP family have been identified: protein (NAIP/BIRC1/NLRB), cellular IAP1/human IAP2/ BIRC2, cellular IAP2/human IAP1/BIRC3, X-linked IAP (XIAP)/BIRC4, survivin/BIRC5, baculoviral IAP repeat-containing ubiquitin-conjugating enzyme/apollon/ BIRC6, Livin/melanoma-IAP/BIRC7/KIAP and inhibitory of apoptosis proteins-like protein-2 (ILP-2)/testis-specific IAP (Ts-IAP)/hILP-2/BIRC8 $(5,7,8)$.

ILP-2 was initially detected in the human testis $(9,10)$ and in our previous study, we showed that ILP-2 is a novel serological biomarker for breast cancer (8). In this study, we identified whether ILP-2 led to breast cancer progression. We analyzed the expression levels of ILP-2 in breast cancer tissue samples by immunohistochemistry, followed by detection of ILP-2 expression in breast cancer cell lines through western blot analysis. We further investigated the influence of ILP-2 in breast cancer growth via MTT assay, scratch assay and acridine orange/ethidium bromide ( $\mathrm{AO} / \mathrm{EB})$ double-staining analysis in ascertaining the specific role of ILP-2 in breast cancer. Furthermore, we knocked down ILP-2 by siRNA to elucidate its role in breast cancer.

\section{Materials and methods}

Statement of Ethics. The present study was approved by Jishou University Ethics Committee (Jishou, China). All participated patients received and approved the written informed consent before joining the study.

Patient samples. Fifty-nine pathological samples were provided by the First Affiliated Hospital, College of Medical Science, Jishou University (Jishou, China). These samples included 35 breast cancer and 24 galactophore hyperplasia tissues. 
The average age of breast cancer patients and galactophore hyperplasia patients was 47 and 32 years, respectively. These samples were collected from July 2013 to October 2013. Breast cancer samples were collected from stage II patients diagnosed according to cancer pathology standards, which are scored on the formation of the gland tumor, the polymorphism of nucleus and the fission count, and designated the infiltrating ductal carcinoma for level I on the total score 3-5, level II on 6-7 and level III on 8-9. In addition, galactophore hyperplasia samples were from breast fibroadenoma patients.

Immunohistochemistry. Tissue paraffin-embedded blocks were cut into $4 \mu \mathrm{m}$-thick slices and pasted on the glass slide. These blocks were dewaxed by dimethylbenzene and dehydrated in graded series of alcohol. Peroxidase was inactivated by incubation with $3 \%$ hydrogen peroxide at $25^{\circ} \mathrm{C}$ for $10 \mathrm{~min}$. Antigens were retrieved by heating a citrate-buffered solution in the microwave for $10 \mathrm{~min}$. Tissue sections were incubated with $5 \%$ bovine serum albumin (BSA) for $13 \mathrm{~min}$ at room temperature and then incubated with ILP-2 (rabbit IgG; dilution 1:500; cat. no. sc-130107; Santa Cruz Biotechnology, Inc., CA, USA) overnight at $4^{\circ} \mathrm{C}$. Slices were visualized with 3,3'-diaminobenzidine kit (Beyotime Institute of Biotechnology, Shanghai, China) for $5 \mathrm{~min}$, and then stained by hematoxylin and examined under light microscopy.

Western blot analysis. HCC-1937, MX-1, MCF-7 and MCF-10A cell lines $\left(5 \times 10^{6}\right.$ cells/cell line) were separately collected and western blot analysis was performed. Briefly, total proteins were extracted from cells with RIPA buffer (20 mM Tris, pH 7.5, $150 \mathrm{mM} \mathrm{NaCl}, 1 \%$ Triton $\mathrm{X}-100,0.1 \%$ SDS and $1 \%$ deoxycholate) containing protease inhibitors. The total protein concentration was determined using a BCA Protein Assay kit (Applygen Technologies Inc., Beijing, China). Thirty micrograms of total protein was separated on a $10 \%$ SDS-polyacrylamide gel and then transferred onto polyvinylidene fluoride (PVDF) membranes (Merck KGaA, Darmstadt, Germany). The membranes were blocked with TBST (Tris-buffered saline and Tween-20) and 5\% skim milk powder for $2 \mathrm{~h}$, then incubated with primary antibodies against ILP-2 (rabbit IgG, 1:1,000; cat. no. Ab9664; Abcam, Cambrige, UK) and tubulin (rabbit IgG, 1:1,000; cat. no. 11224-1-AP; Proteintech Group, Wuhan, China) overnight at $4^{\circ} \mathrm{C}$. On the second day, the membranes were washed by TBST and incubated with a goat anti-rabbit immunoglobulin G-horseradish peroxidase (IgG-HRP) (anti-rabbit IgG, 1:5,000; cat. no. ZB-2301; ZSGB-BIO, Beijing, China) for $1 \mathrm{~h}$ at room temperature. An enhanced chemiluminescence detection system (Super ECL Plus; Applygen Technologies) was used to visualize immunoreactive proteins. The protein band was visualized by chemical chemiluminescence imaging system (Beijing Sage Creation Science Co., Ltd., Beijing, China). The images were analyzed with ImageJ (National Institutes of Health, Bethesda, MD, USA). Tubulin was used as an internal control.

RNA interference (RNAi). According to the manufacturer's instructions, Invitrogen ${ }^{\mathrm{TM}}$ Lipofectamine 2000 (Thermo Fisher Scientific, Inc., MA, USA) and small interfering RNA [siRNA-5, siRNA-3, siRNA-1519, siRNA-1643 and negative control (NC)] (Shanghai GenePharma Co., Ltd., Shanghai, China) were separately gently mixed at a volume ratio of 1:1 and stored for $20 \mathrm{~min}$ at room temperature. Mixed Lipofectamine 2000 and small interfering RNA were added to MCF-7 cells in the logarithmic growth phase and cultivated in $5 \% \mathrm{CO}_{2}$ for $24 \mathrm{~h}$ at $37^{\circ} \mathrm{C}$, wherein the small interfering RNA had a final concentration of $50 \mathrm{nM}$. Interference effects on ILP-2 expression were analyzed via western blot analysis.

Mixed Lipofectamine 2000 and small interfering RNA (siRNA-5, siRNA-3 and NC) were correspondingly added to the HCC-1937, MX-1 and MCF-7 cells in the logarithmic growth phase and cultivated in $5 \% \mathrm{CO}_{2}$ for 24,48 and $72 \mathrm{~h}$ at $37^{\circ} \mathrm{C}$. Total proteins were separately extracted. After determining protein concentration using the BCA kit (Beyotime Institute of Biotechnology, Shanghai, China), proteins were analyzed by western blot analysis.

MTT assays. HCC-1937, MX-1 and MCF-7 cells in the logarithmic phase were simultaneously digested with trypsin, re-suspended in complete culture medium and arranged in four groups: The siRNA-5 group, the siRNA-3 group, the NC group and HCC-1937 or MX-1 or MCF-7 cell group. Four groups of cells were separately seeded on $2 \times 10^{3}$ cells/well in three 96-well plates, wherein every cell group was arranged in 6-wells, incubated in $5 \% \mathrm{CO}_{2}$ for $24 \mathrm{~h}$ at $37^{\circ} \mathrm{C}$ and mixed with the small interfering RNA. Following cultivation of the four cell groups for 24,48 and $72 \mathrm{~h}, 10 \mu \mathrm{l}$ of MTT ( $5 \mathrm{mg} / \mathrm{ml}$ ) (Beijing Dingguo Biotechnology, Beijing, China) was separately added to each well. The medium was discarded $4 \mathrm{~h}$ later and $100 \mu \mathrm{l}$ dimethyl sulfoxide (DMSO; Shanghai Pharmaceutical Group Co., Ltd., Shanghai, China) was added to each well to stop the reaction. After vortexing for $10 \mathrm{~min}$ at room temperature, optical density was measured at $490 \mathrm{~nm}$ using a microplate reader (Biotek ELx800; BioTek Instruments, Winooski, VT, USA).

Scratch assays. Five parallel lines were scratched on the back of a 6-well plate per well. Four groups of HCC-1937, MX-1 and MCF-7 cells in the logarithmic phase, analogous to MTT assay procedure, were simultaneously seeded on $1 \times 10^{4}$ cells/well in a 6-well plate, cultivated in $5 \% \mathrm{CO}_{2}$ for $24 \mathrm{~h}$ at $37^{\circ} \mathrm{C}$, mixed with small interfering RNA and incubated for $24 \mathrm{~h}$. Three vertical scratch wounds were separately made on parallel lines by a sterile pipette tip in the four cell groups. Cells were cultivated in a $5 \% \mathrm{CO}_{2}$ at $37^{\circ} \mathrm{C}$. Three scratch wound areas were measured by an Olympus CKX41 inverted microscope (Olympus Corp., Tokyo, Japan) for 0, 24, 48 and 72 h. Experiments were triplicated.

AO/EB double staining analysis. HCC-1937, MX-1 and MCF-7 cells in the logarithmic growth phase were adhered to coverslips in the well of a 6 -well plate $\left(1 \times 10^{4}\right.$ cells/well $)$ and cultivated in $5 \% \mathrm{CO}_{2}$ for $24 \mathrm{~h}$ at $37^{\circ} \mathrm{C}$. Mixed small interfering RNA (siRNA-5, siRNA-3 and NC) and Lipofectamine 2000 were simultaneously added to the HCC-1937, MX-1 and MCF-7 cells and subsequently cultivated in $5 \% \mathrm{CO}_{2}$ for 24,48 and $72 \mathrm{~h}$ at $37^{\circ} \mathrm{C}$. Culture medium was removed and cells were washed with phosphate-buffered saline (PBS) twice. Dye Reagents 1 and 2 were mixed at a volume ratio of $1: 1$ and diluted by PBS at a ratio of 1:25. Diluted staining agent was dropped into breast 

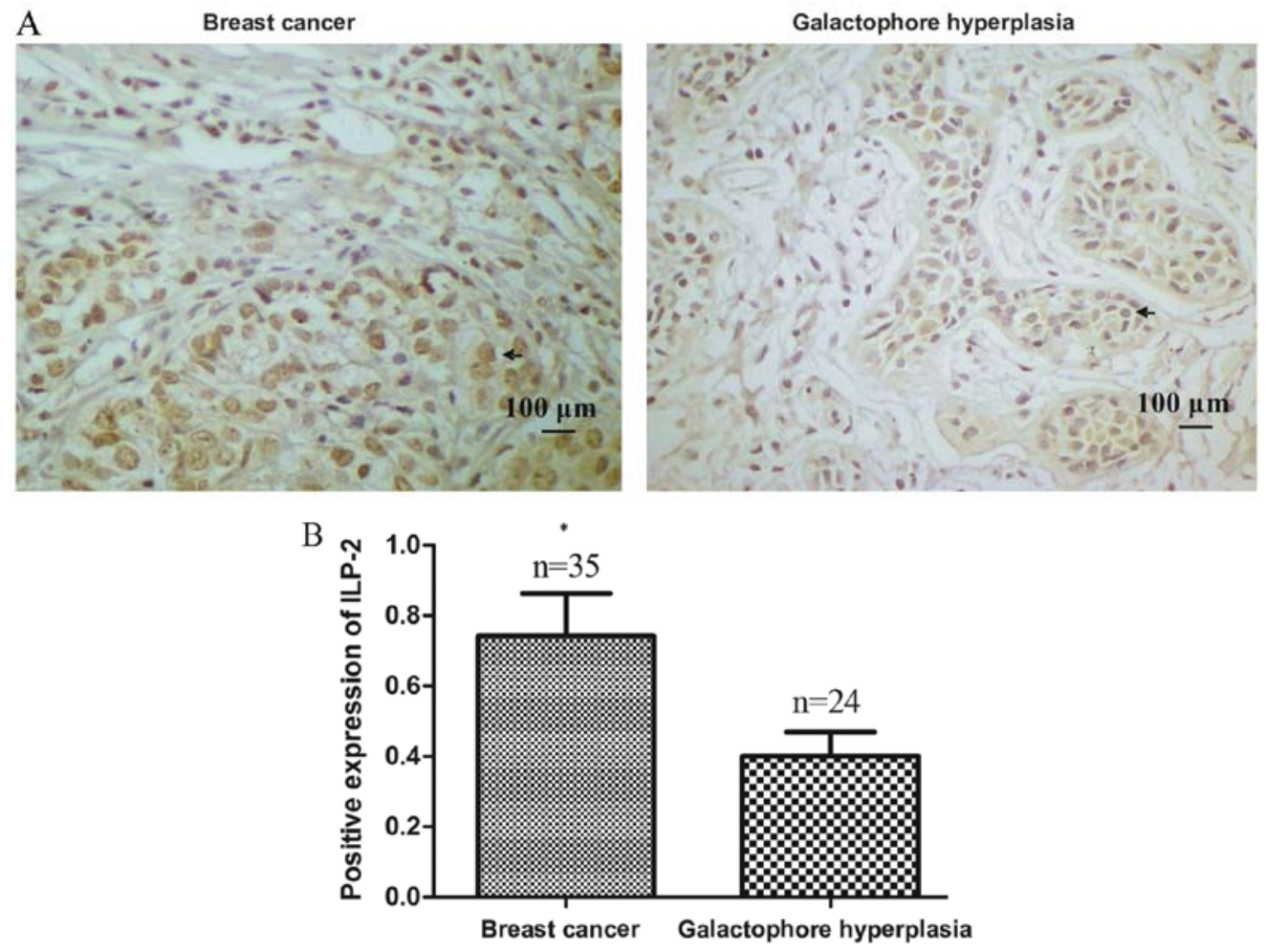

Figure 1. (A) Immunohistochemistry of ILP-2 expression in tissues. Samples of 35 breast cancers and 24 galactophore hyperplasias were analyzed. Scale bar, $100 \mu \mathrm{m}$. (B) The positive rate of breast cancers and galactophore hyperplasias was 62.9 and $25 \%$, respectively. Groups were compared by conducting $\chi^{2}$ test and t-test. ${ }^{*} \mathrm{P}<0.05$ vs. the galactophore hyperplasia samples; $\mathrm{n}=59$.

cancer cells and cultivated in the darkroom for $5 \mathrm{~min}$ at room temperature. Coverslips were examined under an Olympus BX51 inverted fluorescence microscope (Olympus Corp.) at an excitation/emission wavelength of $498 / 516 \mathrm{~nm}$.

Statistical analysis. Histograms were constructed by GraphPad Prism 5 (GraphPad Software, Inc., La Jolla , CA, USA). Statistical analysis was performed by conducting $\chi^{2}$ test, t-test, one-way ANOVA, or post hoc Bonferroni tests by SPSS statistics 17.0 (SPSS, Inc., Chicago, IL, USA). A level of $\mathrm{P}<0.05$ was considered statistically significant.

\section{Results}

Breast cancer tissues have high ILP-2 expression. Paraffin-embedded blocks were analyzed using immunohistochemical analysis to investigate ILP-2 protein expression in the tissues. As shown in Fig. 1A and B, expression levels of ILP-2 in breast cancer tissues were significantly increased in comparison to levels noted in the galactophore hyperplasia tissues $(\mathrm{P}<0.05)$. In addition, positive rates of ILP-2 expression in breast cancers were higher than that in the galactophore hyperplasias (Table I) $\left(\chi^{2}=8.183, \mathrm{P}<0.01\right)$. Our results indicate high ILP-2 expression levels in breast cancer tissues.

ILP-2 is highly expressed in breast cancer cells. Western blot analysis was employed to analyze ILP-2 expression in the 4 breast cancer cell lines. As shown in Fig. 2, protein expression levels of ILP-2 in the breast cancer cell lines such as HCC-1937 $(\mathrm{P}<0.05)$, MX-1 $(\mathrm{P}<0.01)$ and MCF-7 $(\mathrm{P}<0.01)$ were significantly increased when compared with that of the
Table I. Immunohistochemical analysis of ILP-2 in breast tissues.

Protein expression of ILP-2

\begin{tabular}{|c|c|c|c|c|}
\hline Group & $\mathrm{n}$ & Positive & Negative & Positive rate (\%) \\
\hline Breast cancer & 35 & 22 & 13 & $62.9^{\mathrm{a}}$ \\
\hline $\begin{array}{l}\text { Galactophore } \\
\text { hyperplasia }\end{array}$ & 24 & 6 & 18 & 25 \\
\hline
\end{tabular}

$\chi^{2}=8.183 ;$ a $<<0.01$.ILP-2, inhibitor of apoptosis protein-like protein-2.

breast epithelial cell line MCF-10A. These results corroborate the immunohistochemical results, evidencing the highly expressed levels of ILP-2 breast cancer cells.

siRNA-5 sequence inhibits ILP-2 expression in breast cancer cell lines. We employed western blot analysis to analyze the interference effect of five siRNAs on ILP-2 expression in the MCF-7 cell line. As shown in Fig. 3, when ILP-2 was specifically knocked down by five siRNAs (siRNA-5, siRNA-3, NC, siRNA-1519 and siRNA-1643), which follow the sequences as depicted in Table II, ILP-2 expression was notably decreased in the siRNA-5 group $(\mathrm{P}<0.001)$ in comparison to that of the MCF-7 group. These results indicate that the siRNA-5 sequence show the highest interference efficiency on ILP-2 expression. 
Table II. siRNA sequences.

\begin{tabular}{llc}
\hline Name & \multicolumn{1}{c}{ Sense (5'-3') } & Antisense (5'-3') \\
\hline siRNA-5 & CUAUACGAAUGGGAUUUGATT & UCAAAUCCCAUUCGUAUAGTT \\
siRNA-3 & UGGUACAAACUACCAAGAATT & UUCUUGGUAGUUUGUACCATT \\
siRNA-1519 & GGUACAAACUACCAAGAAATT & UUUCUUGGUAGUUUGUACCTT \\
siRNA-1643 & GAGGAAAGAAUUCAAACAUTT & AUGUUUGAAUUCUUUCCUCTT \\
Negative control & UUCUCCGAACGUGUCACGUTT & ACGUGACACGUUCGGAGAATT
\end{tabular}
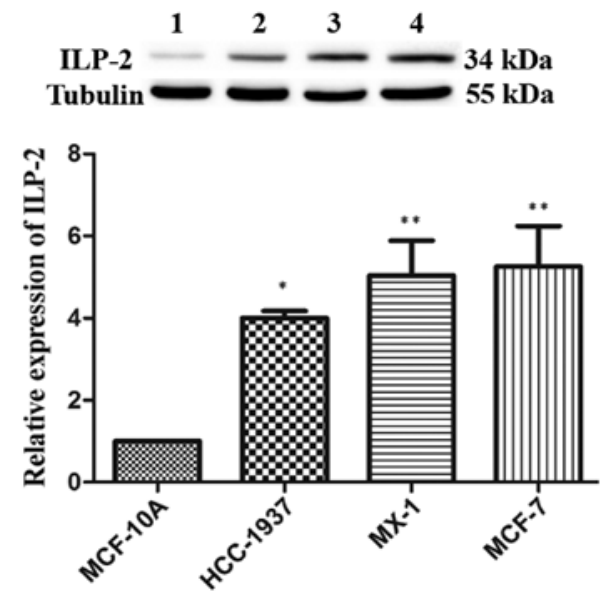

Figure 2. Western blot analysis indicating ILP-2 protein expression in MCF-10A, HCC-1937, MX-1 and MCF-7 cell lines. The results showed that ILP-2 expression in the HCC-1937, MX-1 and MCF-7 cell lines was significantly increased when compared to that of the MCF-10A cells. Lanes 1, 2, 3 and 4 separately indicate the protein expression level in the MCF-10A, HCC-1937, MX-1 and MCF-7 cell lines. ${ }^{*} \mathrm{P}<0.05,{ }^{* *} \mathrm{P}<0.01$ vs. the MCF-10A cells. Data are expressed as mean \pm SEM by ANOVA. Groups were compared by conducting Bonferroni test; $\mathrm{n}=3$.

As illustrated in Fig. 4, in the HCC-1937 cell line, the siRNA-5 group exhibited significantly decreased ILP-2 expression similar to that of the control HCC-1937 group (24 and $48 \mathrm{~h}, \mathrm{P}<0.05 ; 72 \mathrm{~h}, \mathrm{P}<0.01$ ). Likewise in the MX-1 cell line, the siRNA-5 group exhibited significantly decreased ILP-2 expression at $48 \mathrm{~h}(\mathrm{P}<0.001)$ and $72 \mathrm{~h}(\mathrm{P}<0.05)$ when compared with that of the control MX-1 group. In the MCF-7 cell line, ILP-2 expression in the siRNA-5 group was significantly decreased at $48 \mathrm{~h}(\mathrm{P}<0.05)$ and $72 \mathrm{~h}(\mathrm{P}<0.01)$ when compared with that of the MCF-7 group.

ILP-2 positively influences the cell viability of breast cancer cell lines. MTT assays were performed to examine cell viability when ILP-2 expression was knocked down by siRNA sequences for 24, 48 and $72 \mathrm{~h}$ in the HCC-1937, MX-1 and MCF-7 cell lines respectively so as to determine the role of ILP-2 in breast cancer cell growth. As shown in Fig. 5, cell viability of the siRNA-5 groups was significantly reduced when compared to that of the control group (Fig. 5A and C, P<0.001; Fig. 5B, 24 and $48 \mathrm{~h}, \mathrm{P}<0.001,72 \mathrm{~h}, \mathrm{P}<0.01$ ), thus, indicating that ILP-2 positively promotes the growth of breast cancer cells.

ILP-2 is actively involved in the cell migration of breast cancer cell lines. Scratch assays were performed to study the rate of

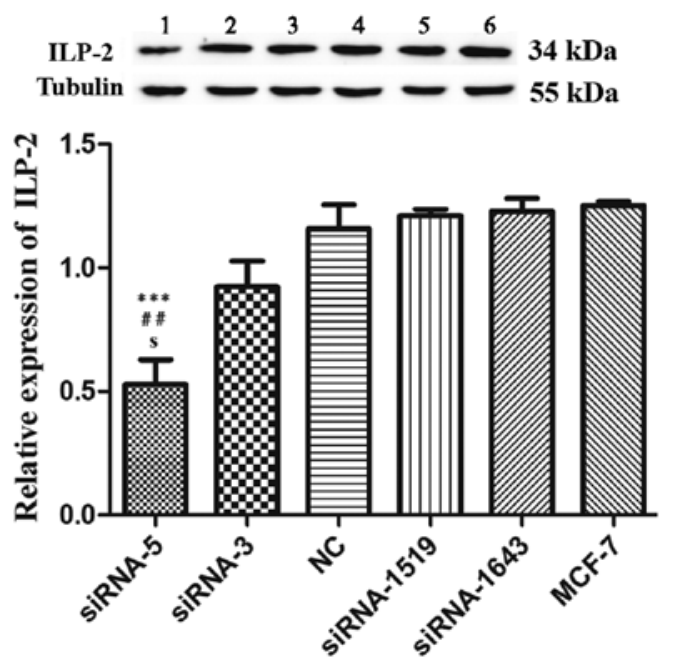

Figure 3. Western blot analysis showing ILP-2 protein expression in MCF-7 cells following knockdown of ILP-2. The data indicate that knockdown by the siRNA-5 sequence resulted in decreased ILP-2 expression in MCF-7 cells in comparison to the MCF-7 group. Lanes 1, 2, 3, 4, 5 and 6 separately indicate the expression of ILP-2 in the siRNA-5, siRNA-3, NC, siRNA-1519, siRNA-1643 and MCF-7 group. ${ }^{* * *} \mathrm{P}<0.001$ vs. the $\mathrm{MCF}-7$ group; ${ }^{\# \#} \mathrm{P}<0.01$ vs. the NC group; ${ }^{\mathrm{P}}<0.05$ vs. the siRNA-3 group. Data are expressed as mean \pm SEM by ANOVA. Groups were compared by conducting Bonferroni test; $\mathrm{n}=3$.

cell migration in ILP-2 siRNA knockdown cell lines such as HCC-1937, MX-1 and MCF-7 so as to ascertain whether ILP-2 is involved in breast cancer cell migration. As shown in Fig. 6A-C, the rate of cell migration of the siRNA-5 group was significantly decreased in comparison to that of the control group (Fig. 6A, 24 h, $\mathrm{P}<0.001,48$ and $72 \mathrm{~h}, \mathrm{P}<0.01$; Fig. 6B, $24 \mathrm{~h}, \mathrm{P}<0.01,48 \mathrm{~h}, \mathrm{P}<0.001,72 \mathrm{~h}, \mathrm{P}<0.05$; Fig. $6 \mathrm{C}, 24 \mathrm{~h}, \mathrm{P}<0.01$, $48 \mathrm{~h}, \mathrm{P}<0.05,72 \mathrm{~h}, \mathrm{P}<0.001$ ), with results implying that ILP-2 positively accelerates the migration of breast cancer cells.

ILP-2 inhibits the apoptosis of breast cancer cells. Considering the effect of ILP-2 on the apoptosis of breast cancer cells, dual AO/EB staining analysis was separately used to detect HCC-1937, MX-1 and MCF-7 cell apoptosis when ILP-2 was knocked down for 24, 48 and $72 \mathrm{~h}$ to further determine the role of ILP-2 on breast cancer cell growth. As shown in Fig. 7A-C, the apoptosis rate of the siRNA-5 group was significantly increased when compared with that of the control group $(\mathrm{P}<0.001$ at all times for all cell lines), with results indicating that ILP-2 positively inhibits the apoptosis of breast cancer cells and promotes the growth of breast cancer cells. 

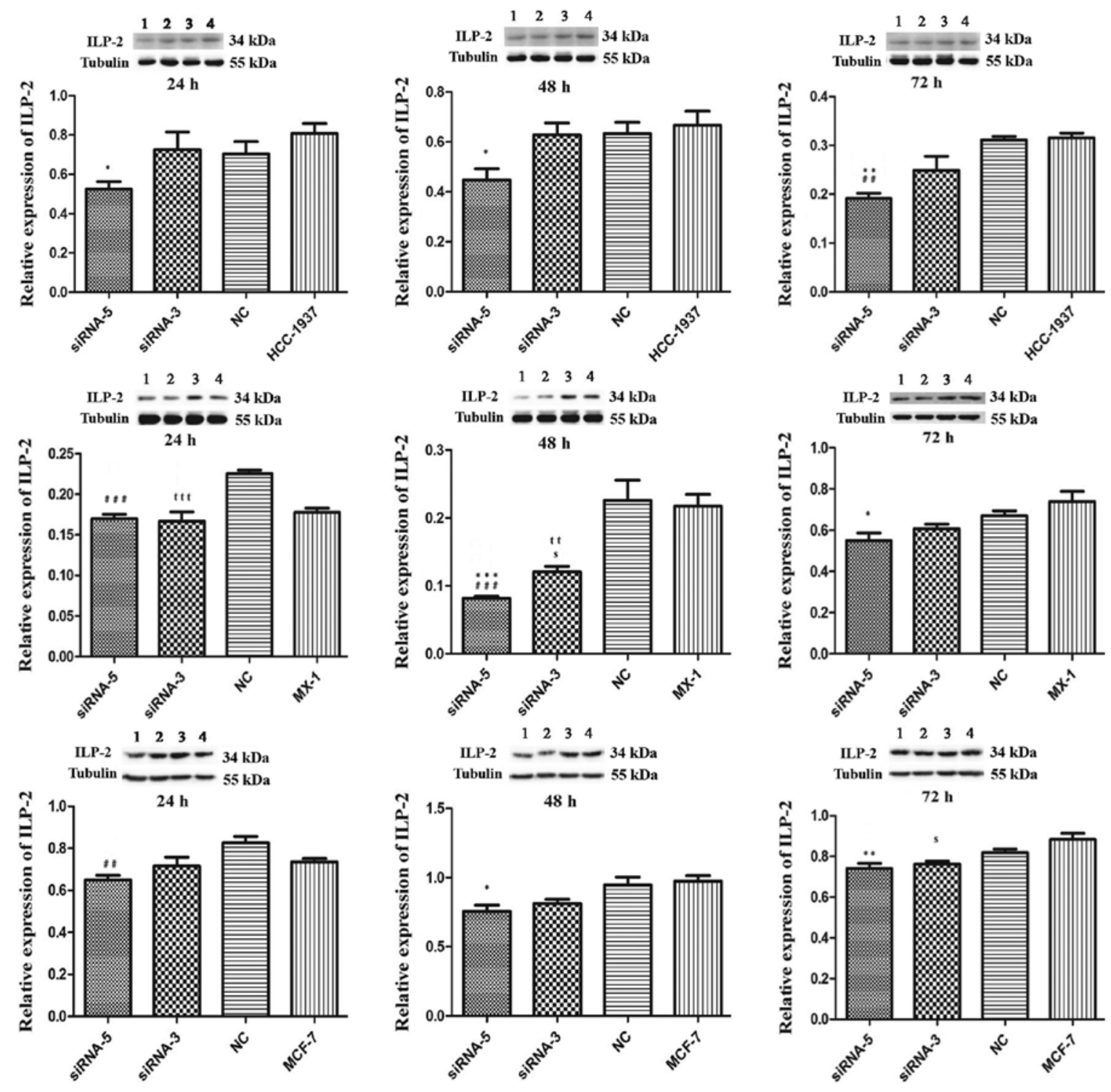

Figure 4. Western blot analysis showing the expression of ILP-2 in the HCC-1937, MX-1 and MCF-7 cell lines following knockdown of ILP-2 for 24,48 and $72 \mathrm{~h}$. Lanes 1, 2, 3 and 4 separately indicate ILP-2 expressions in siRNA-5, siRNA-3, NC and HCC-1937 or MX-1 or MCF-7 group. In regards to the HCC-1937 cell line, expression of ILP-2 was significantly decreased in the siRNA-5 group compared to the HCC-1937 group. ${ }^{\mathrm{P}}<0.05,{ }^{* * *} \mathrm{P}<0.01$ vs. the HCC-1937 group; ${ }^{\# \#} \mathrm{P}<0.01$ vs. the NC group. In regards to the MX-1 cell line, ILP-2 expression was significantly decreased when compared to the MX-1 group following the knockdown by the siRNA-5 sequence for 48 and $72 \mathrm{~h} .{ }^{*} \mathrm{P}<0.05,{ }^{* * * *} \mathrm{P}<0.001$ vs. the MX-1 group; ${ }^{\# \# "} \mathrm{P}<0.001$ vs. the NC group; ${ }^{\text {tt}} \mathrm{P}<0.01$, ${ }^{\text {tt }} \mathrm{P}<0.001 \mathrm{vs}$. the NC group; ${ }^{\mathrm{P}} \mathrm{P}<0.05$ vs. the MX-1group. In regards to the MCF-7 cell line, ILP-2 expression was significantly decreased when compared to MCF-7 group after knockdown by the siRNA-5 sequence for 48 and $72 \mathrm{~h}$. ${ }^{*} \mathrm{P}<0.05,{ }^{* *} \mathrm{P}<0.01$ vs. the MCF-7 group; ${ }^{\# \#} \mathrm{P}<0.01$ vs. the NC group; ${ }^{\text {s }}<0.05$ vs. the MCF-7 group. Data are expressed as mean \pm SEM by ANOVA. Groups were compared by conducting Bonferroni test; $n=3$.
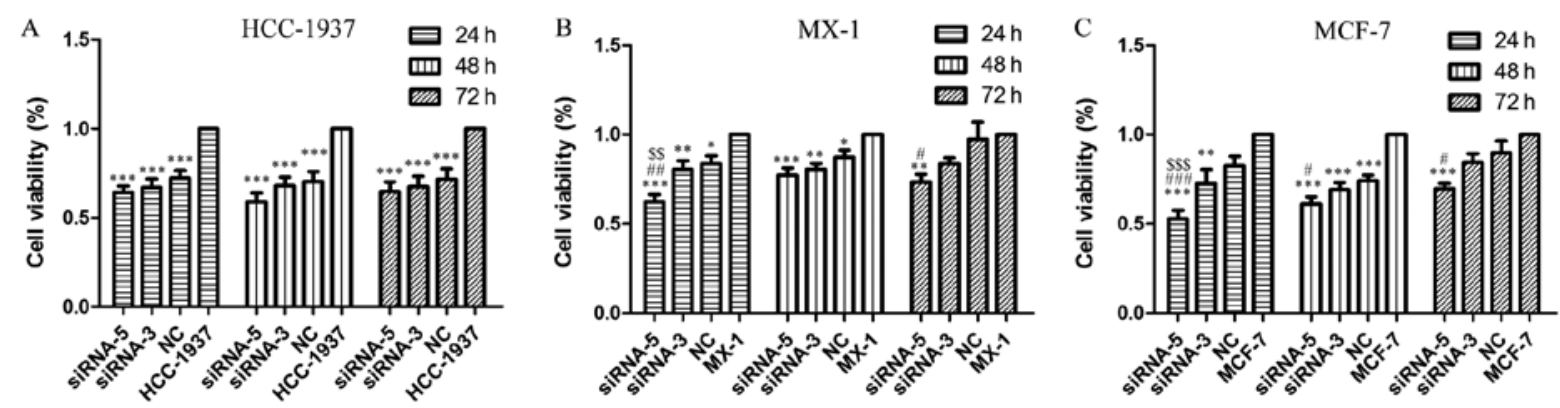

Figure 5. MTT assay demonstrating the cell viability of HCC-1937, MX-1 and MCF-7 cell lines when ILP-2 was separately knocked down for 24,48 and $72 \mathrm{~h}$. In regards to the HCC-1937 cell line, the cell viability of the siRNA-5 group was notably decreased when compared to the HCC-1937 group. ${ }^{* * *} \mathrm{P}<0.001$ vs. the HCC-1937 group. In regards to the MX-1 cell line, cell viability of the siRNA-5 group was significantly decreased when compared to the MX-1 group. "P<0.05, ${ }^{* *} \mathrm{P}<0.01,{ }^{* * *} \mathrm{P}<0.001$ vs. the MX-1 group; ${ }^{\#} \mathrm{P}<0.05,{ }^{\# \#} \mathrm{P}<0.01$ vs. the NC group; ${ }^{\$ \$} \mathrm{P}<0.01$ vs. the siRNA-3 group. In regards to the MCF-7 cell line, cell viability of the siRNA-5 group was significantly decreased when compared to the MCF-7 group. ${ }^{* * *} \mathrm{P}<0.01,{ }^{* * *} \mathrm{P}<0.001$ vs. the MCF-7 group; ${ }^{\# \mathrm{P}}<0.05$, ${ }^{\# \# \#} \mathrm{P}<0.001$ vs. the $\mathrm{NC}$ group; ${ }^{\$ \$ \$} \mathrm{P}<0.001$ vs. the siRNA-3 group. Data are expressed as mean \pm SEM by ANOVA. Groups were compared by conducting Bonferroni test; $\mathrm{n}=6$. 

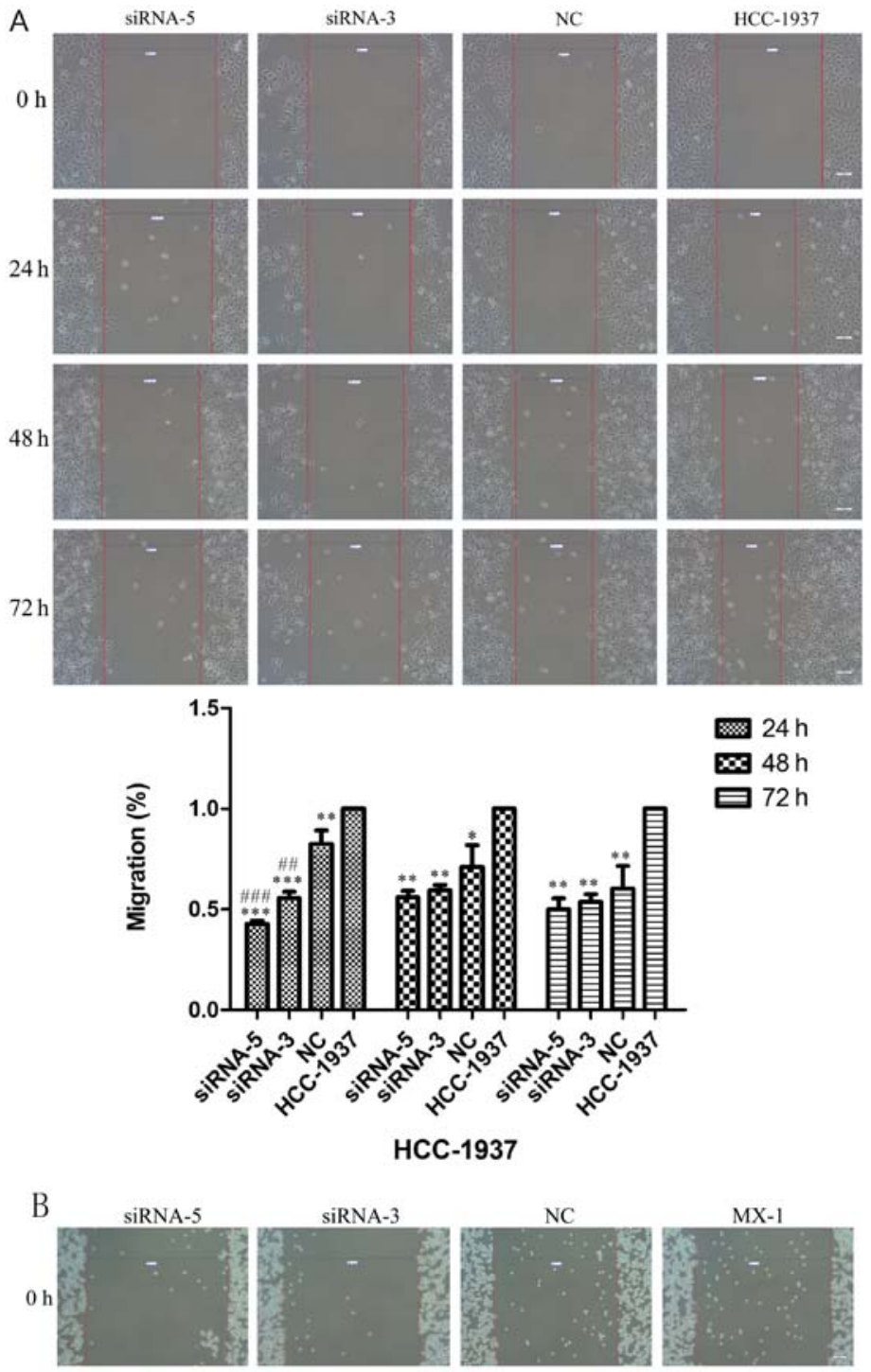

$\mathrm{MX}-1$
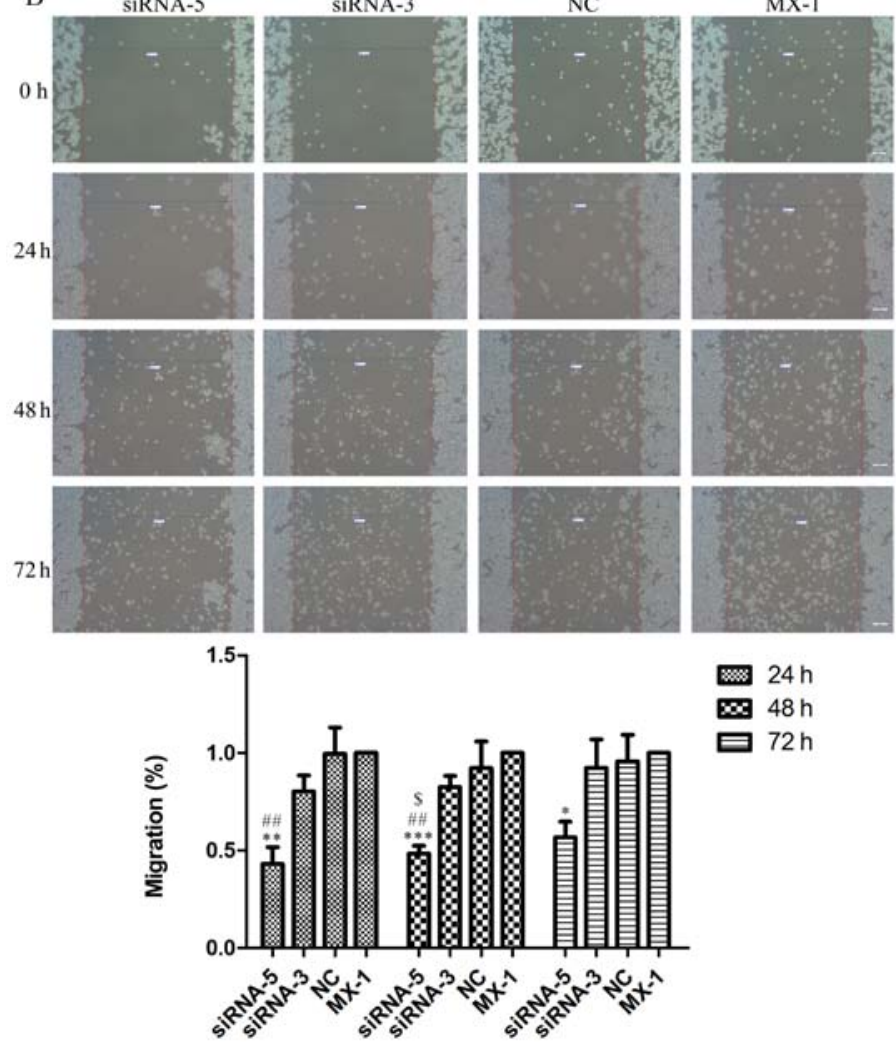

$\infty 48 \mathrm{~h}$

曰72h

Figure 6. Scratch analysis showing the rate of cell migration of the HCC-1937, MX-1 and MCF-7 cell lines when ILP-2 was separately knocked down for 24, 48 and $72 \mathrm{~h}$. (A) In regards to the HCC-1937 cell line, the rate of cell migration of the siRNA-5 group was notably decreased compared to the HCC-1937 group. ${ }^{*} \mathrm{P}<0.05,{ }^{* *} \mathrm{P}<0.01,{ }^{* * *} \mathrm{P}<0.001$ vs. the HCC-1937 group, ${ }^{\# \#} \mathrm{P}<0.01,{ }^{\# \# \#} \mathrm{P}<0.001$ vs. the NC group. (B) In regards to the MX-1 cell line, the rate of cell migration of the siRNA-5 group was notably decreased compared to the MX-1 group. ${ }^{*} \mathrm{P}<0.05,{ }^{* *} \mathrm{P}<0.01,{ }^{* * * *} \mathrm{P}<0.001$ vs. the MX-1 group; ${ }^{\# / 4} \mathrm{P}<0.01$ vs. the NC group; ${ }^{\$} \mathrm{P}<0.05$ vs. the siRNA-3 group. 


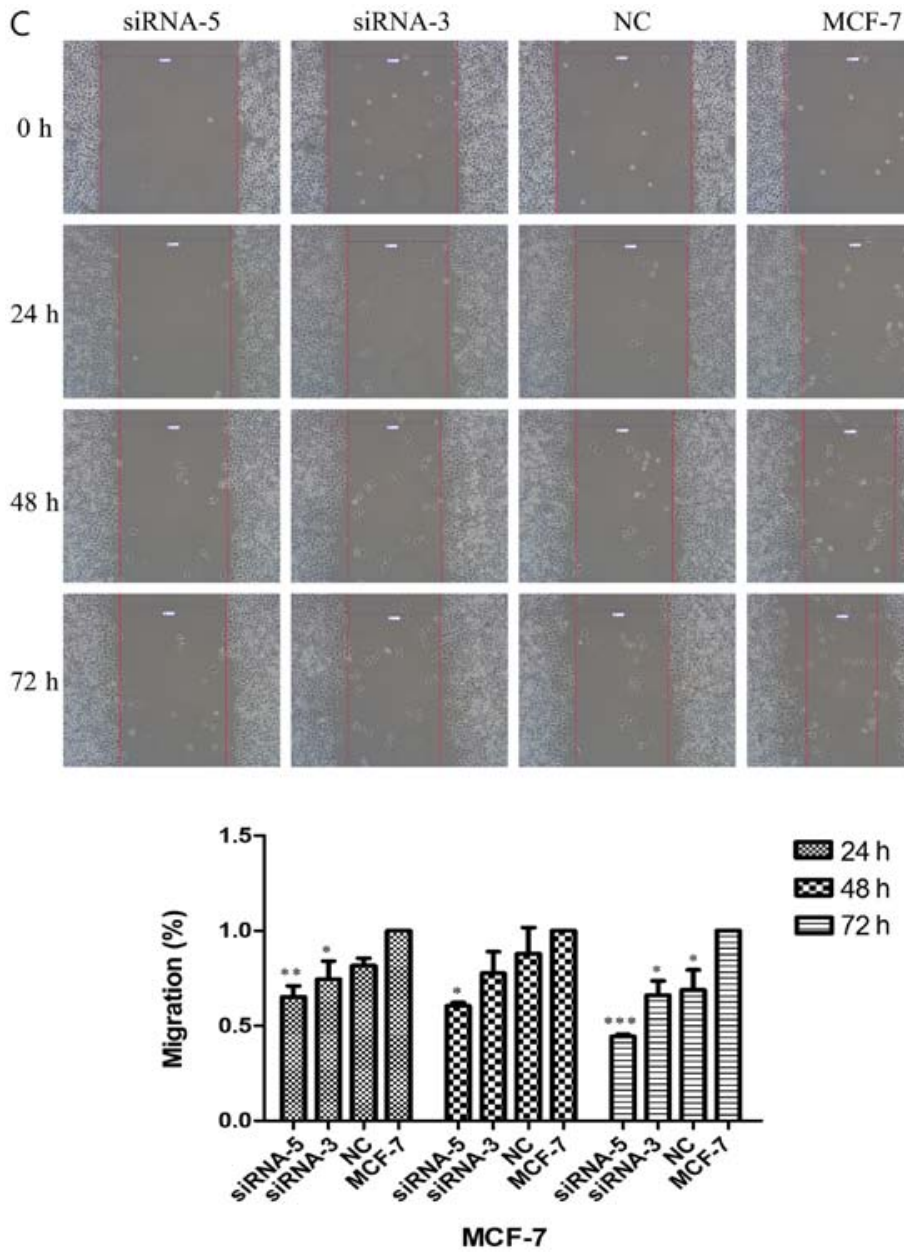

Figure 6. Continued. (C) In regards to the MCF-7 cell line, the rate of cell migration of the siRNA-5 group was notably decreased compared to the MCF-7 group. ${ }^{*} \mathrm{P}<0.05,{ }^{* * *} \mathrm{P}<0.01,{ }^{* * *} \mathrm{P}<0.001$ vs. the MCF-7 group. Data are expressed as mean \pm SEM by ANOVA. Groups were compared by conducting Bonferroni test. Scale bar, $200 \mu \mathrm{m} ; \mathrm{n}=3$.

\section{Discussion}

ILP-2 is a novel apoptotic inhibitory protein closely correlated to caspase-9 (9). ILP-2/BIRC-8 was found to inhibit HepG2 cell apoptosis and promote cell growth (11). Based on the results from the present study, we hypothesize that ILP-2 accelerates the growth of breast cancer cells.

Initially, ILP-2 was found to be solely expressed in the testis of normal tissues $(9,10)$. It was later detected in lymphoblastoid cells (9). In our prior published study, we demonstrated high ILP-2 expression in breast cancer patient sera (8). In the present study, we found high ILP-2 expression in the breast cancer tissues and breast cancer cells. Livin protein expression is elevated in breast cancer tissues and cell lines, which in turn promotes the progression and metastasis of breast cancer (12). Our present results indicate that ILP-2 plays an active role in breast cancer cell growth.

XIAP (ILP-1) and Livin are members of the IAP family, with a very similar domain to ILP-2 (4). RNAi technology can distinctively inhibit ILP-1 and Livin expression (7,13-19). We applied RNAi technology to knock down ILP-2 expression and analyzed its role in breast cancer cell growth. Our results demonstrated that siRNA- 5 can inhibit the protein expression of ILP-2 in breast cancer cells.
Livin participates in proliferation, migration and invasion of breast cancer (20). Overexpression of Livin promotes the migratory and invasive abilities of MCF-7, with knockdown of Livin exhibiting contrasting effect (12). After inhibiting ILP-2 expression using siRNA-5 in breast cancer cells such as HCC-1937, MX-1 and MCF-7 cell lines, cell viability and rate of cell migration were respectively significantly decreased, the cell apoptosis rate was separately significantly increased. These results suggest that ILP-2 vigorously promotes breast cancer cell growth.

In conclusion, our experiment confirms the hypothesis that ILP-2 plays a significant role in the growth of breast cancer cells and is a novel growth enhancer for breast cancer. However, further mechanistic studies need to be carried out to examine how ILP-2 promotes breast cancer cell growth. Accordingly, we plan to further explore the underlying mechanism of the growth-promoting activity of ILP-2 in breast cancer cells. First, we will apply the co-immunoprecipitation technology to search the protein which can interact with ILP-2 and verify it. In addition, we will construct Lenti-ILP-2-shRNA which knocks down the expression of ILP-2, transfect it into MCF-7 cells and filtrate the stably transfected MCF-7 cells by addition of the puromycin to MCF-7 cells. The stably transfected MCF-7 cells can be applied to establish human breast 

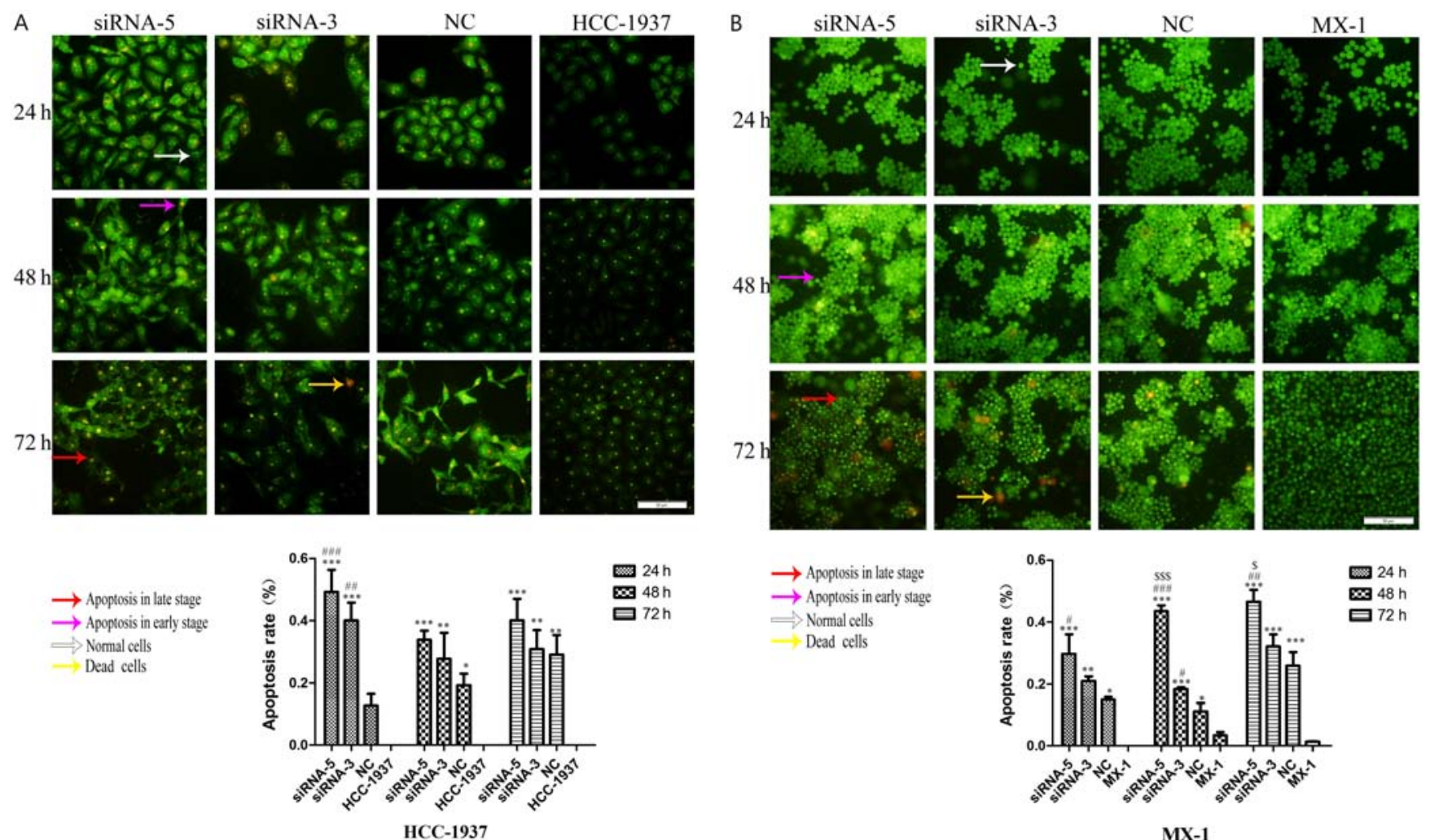

$48 \mathrm{~h}$
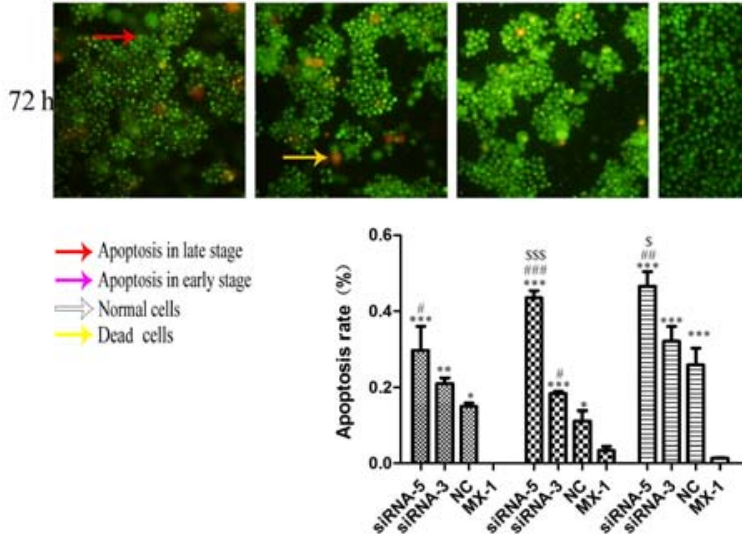

$24 h$

C

SiRNA-5

SiRNA-3
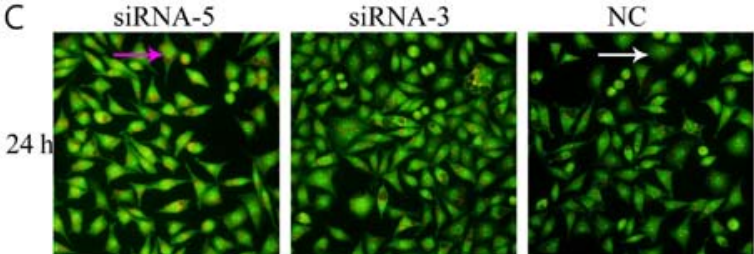

MCF-7
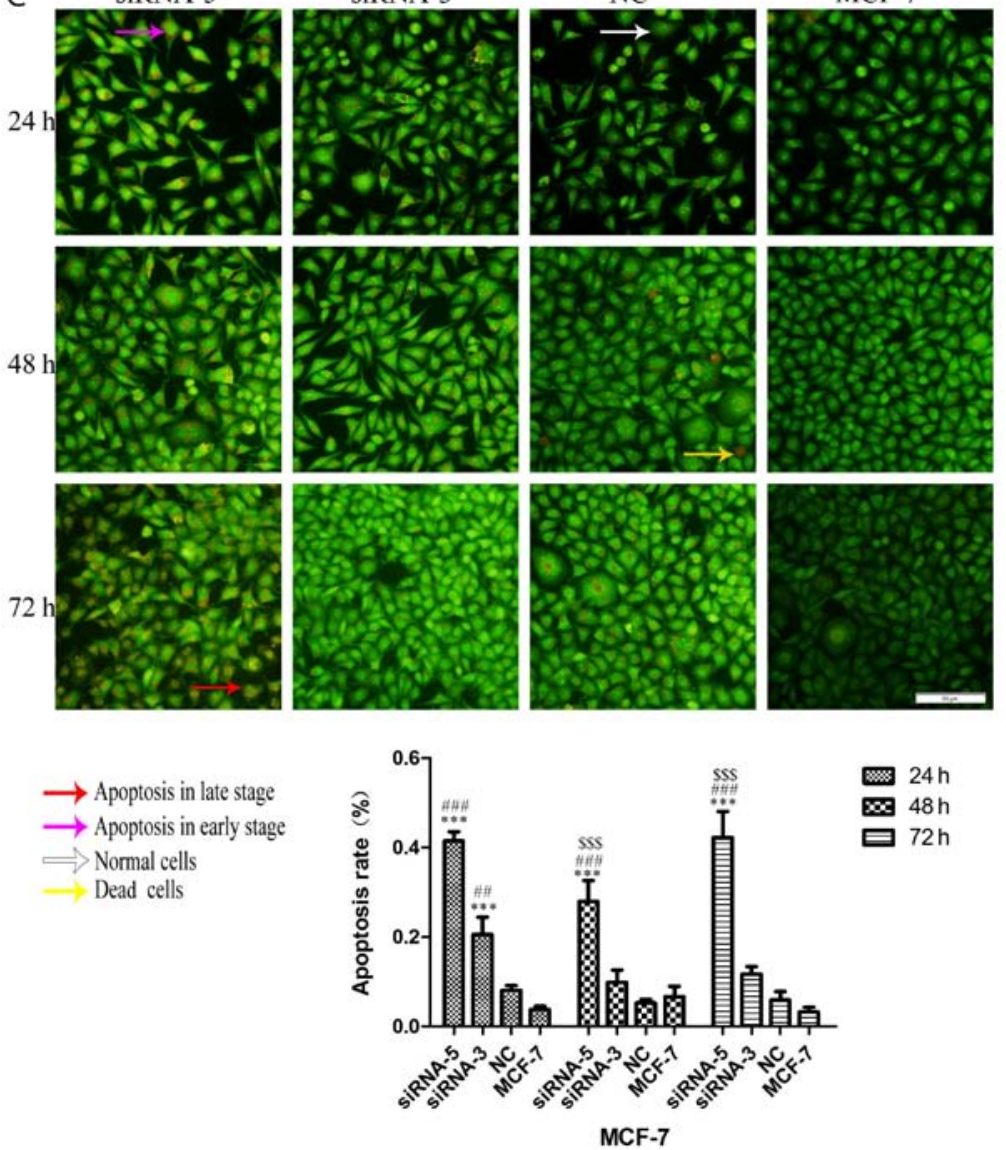

$24 \mathrm{~h}$

$\infty 48 \mathrm{~h}$

$\Longrightarrow$ Normal cells

Figure 7. AO-EB double staining analysis showing the apoptotic rate of HCC-1937, MX-1 and MCF-7 cell lines when ILP-2 was separately knocked down for 24, 48 and $72 \mathrm{~h}$. (A) In regards to the HCC-1937 cell line, the apoptosis rate of the siRNA-5 group was notably increased when compared to the HCC-1937 group. ${ }^{*} \mathrm{P}<0.05,{ }^{* *} \mathrm{P}<0.01,{ }^{* * *} \mathrm{P}<0.001$ vs. the HCC-1937 group; ${ }^{\# \#} \mathrm{P}<0.01,{ }^{\# \# \#} \mathrm{P}<0.001$ vs. the NC group. (B) In regards to the MX-1 cell line, the apoptotic rate of the siRNA-5group was notably increased when compared to the MX-1 group. ${ }^{*} \mathrm{P}<0.05,{ }^{* *} \mathrm{P}<0.01,{ }^{* * * *} \mathrm{P}<0.001$ vs. the MX-1 group; ${ }^{\#} \mathrm{P}<0.05$, ${ }^{\# \#} \mathrm{P}<0.01,{ }^{\# \# "} \mathrm{P}<0.001$ vs. the NC group; ${ }^{~} \mathrm{P}<0.05,{ }^{\$ s \$} \mathrm{P}<0.001$ vs. the siRNA-3 group. (C) In regards to the MCF-7 cell line, the apoptotic rate of the siRNA-5 group was notably increased when compared to the MCF-7 group. ${ }^{* * *} \mathrm{P}<0.001$ vs. the MCF-7 group; ${ }^{\# \#} \mathrm{P}<0.01,{ }^{\# \# *} \mathrm{P}<0.001$ vs. the NC group; ${ }^{\$ \$ \$} \mathrm{P}<0.001$ vs. the siRNA-3 group. Data are expressed as mean \pm SEM by ANOVA. Groups were compared by conducting Bonferroni test. Scale bar, $100 \mu \mathrm{m} ; \mathrm{n}=5$. 
cancer xenografts in nude mice. When the solid tumors are successfully grown, we will excise them, draw growth cures after measuring the solid tumor size and analyze the expression of the ILP-2 downstream gene in its pathway by using the solid tumors.

\section{Acknowledgements}

We thank Dr Benson O.A. Botchway and Dr Akhileshwar Namani (Zhejiang University School of Medicine) for having critically revised the manuscripts.

\section{Funding}

The present study was supported by the National Natural Science Foundation of China (no. 81360397), the Scientific Research Project in Jishou University (no. Jdy16024) and the Scientific Research Project for Graduates in JiShou University (no. JGY201772).

\section{Availability of data and materials}

All data generated or analyzed in this study are included in this published article.

\section{Authors' contributions}

MX designed the manuscript and was also involved in the conception of the study; LZ, WZ, XZ and SX wrote the manuscript, collected clinical information and performed the statistical analyses; MW, XP, YP, BL, PT, QC and DY assisted with the immunohistochemistry and western blotting; ZC, ZS, SW and KY assisted with MTT assays, scratch assays and $\mathrm{AO} / \mathrm{EB}$ double staining analysis. All authors read and approved the manuscript and agree to be accountable for all aspects of the research in ensuring that the accuracy or integrity of any part of the work is appropriately investigated and resolved.

\section{Ethics approval and consent to participate}

The present study was approved by the Ethics Committee of Jishou University (Jishou, China). All participated patients received and approved the written informed consent before joining the study.

\section{Patient consent for publication}

Not applicable.

\section{Competing interests}

The authors declare that they have no competing interests.

\section{References}

1. Lopez J and Meier P: To fight or die-inhibitor of apoptosis proteins at the crossroad of innate immunity and death. Curr Opin Cell Biol 22: 872-881, 2010.

2. Hanahan D and Weinberg RA: Hallmarks of cancer: The next generation. Cell 144: 646-674, 2011.
3. de Almagro MC and Vucic D: The inhibitor of apoptosis (IAP) proteins are critical regulators of signaling pathways and targets for anti-cancer therapy. Exp Oncol 34: 200-211, 2012.

4. LaCasse EC, Mahoney DJ, Cheung HH, Plenchette S, Baird S and Korneluk RG: IAP-targeted therapies for cancer. Oncogene 27: 6252-6275, 2008

5. Saleem M, Qadir MI, Perveen N, Ahmad B, Saleem U, Irshad T and Ahmad B: Inhibitors of apoptotic proteins: New targets for anticancer therapy. Chem Biol Drug Des 82: 243-251, 2013.

6. Liston P, Roy N, Tamai K, Lefebvre C, Baird S, Cherton-Horvat G, Farahani R, McLean M, Ikeda JE, MacKenzie A, et al: Suppression of apoptosis in mammalian cells by NAIP and a related family of IAP genes. Nature 379: 349-353, 1996.

7. Hiscutt EL, Hill DS, Martin S, Kerr R, Harbottle A, Birch-Machin M, Redfern CP, Fulda S, Armstrong JL and Lovat PE: Targeting X-linked inhibitor of apoptosis protein to increase the efficacy of endoplasmic reticulum stress-induced apoptosis for melanoma therapy. J Invest Dermatol 130: 2250-2258, 2010

8. Xiang M, Zhou W, Gao D, Fang X and Liu Q: Inhibitor of apoptosis protein-like protein-2 as a novel serological biomarker for breast cancer. Int J Mol Sci 13: 16737-16750, 2012.

9. Richter BW, Mir SS, Eiben LJ, Lewis J, Reffey SB, Frattini A, Tian L, Frank S, Youle RJ, Nelson DL, et al: Molecular cloning of ILP-2, a novel member of the inhibitor of apoptosis protein family. Mol Cell Biol 21: 4292-4301, 2001.

10. Wang L, Zhang Q, Liu B, Han M and Shan B: Challenge and promise: roles for Livin in progression and therapy of cancer. Mol Cancer Ther 7: 3661-3669, 2008.

11. Chuturgoon AA, Phulukdaree A and Moodley D: Fumonisin $B_{1}$ inhibits apoptosis in HepG2 cells by inducing Birc-8/ILP-2. Toxicol Lett 235: 67-74, 2015.

12. Han Y, Zhang L, Wang W, Li J and Song M: Livin promotes the progression and metastasis of breast cancer through the regulation of epithelial-mesenchymal transition via the p38/GSK $3 \beta$ pathway. Oncol Rep 38: 3574-3582, 2017.

13. Chen J, Xiao XQ, Deng CM, Su XS and Li GY: Downregulation of xIAP expression by small interfering RNA inhibits cellular viability and increases chemosensitivity to methotrexate in human hepatoma cell line HepG2. J Chemother 18: 525-531, 2006.

14. Buneker CK, Yu R, Deedigan L, Mohr A and Zwacka RM: IFN- $\gamma$ combined with targeting of XIAP leads to increased apoptosis-sensitisation of TRAIL resistant pancreatic carcinoma cells. Cancer Lett 316: 168-177, 2012.

15. Wang S, Bai L, Lu J, Liu L, Yang CY and Sun H: Targeting inhibitors of apoptosis proteins (IAPs) for new breast cancer therapeutics. J Mammary Gland Biol Neoplasia 17: 217-228, 2012.

16. Liu H, Wang S, Sun H, Pan Z, Zhou W and Wu M: Inhibition of tumorigenesis and invasion of hepatocellular carcinoma by siRNA-mediated silencing of the livin gene. Mol Med Rep 3: 903-907, 2010.

17. Wang TS, Ding QQ, Guo RH, Shen H, Sun J, Lu KH, You SH, Ge HM, Shu YQ and Liu P: Expression of livin in gastric cancer and induction of apoptosis in SGC-7901 cells by shRNA-mediated silencing of livin gene. Biomed Pharmacother 64: 333-338, 2010.

18. Dasgupta A, Alvarado CS, Xu Z and Findley HW: Expression and functional role of inhibitor-of-apoptosis protein livin (BIRC7) in neuroblastoma. Biochem Biophys Res Commun 400: 53-59, 2010.

19. Yang D, Song X, Zhang J, Ye L, Wang S, Che X, Wang J, Zhang $Z$ and Wang L: Suppression of livin gene expression by siRNA leads to growth inhibition and apoptosis induction in human bladder cancer T24 cells. Biosci Biotechnol Biochem 74: 1039-1044, 2010.

20. Li CJ, Cong Y, Liu XZ, Zhou X, Shi X, Wu SJ, Zhou GX and $\mathrm{Lu}$ M: Research progress on the livin gene and osteosarcomas. Asian Pac J Cancer Prev 15: 8577-8579, 2014. International (CC BY-NC-ND 4.0) License. 